\title{
A time-use study of community health worker service activities in three rural districts of Tanzania (Rufiji, Ulanga and Kilombero)
}

Kassimu Tani ${ }^{*}$, Allison Stone², Amon Exavery ${ }^{1}$, Mustafa Njozi ${ }^{1}$, Colin D. Baynes², James F. Phillips² and Almamy Malick Kanté ${ }^{1,2}$

\begin{abstract}
Background: Despite expanding international commitment to community health worker (CHW) deployment, little is known about how such workers actually use their time. This paper investigates this issue for paid CHWs named "Community Health Agents," which in Swahili is "Wawezeshaji wa Afya ya Jamii" ("WAJA"), trained for 9 months in primary health care service delivery and deployed to villages as subjects of a randomized trial of their impact on childhood survival in three rural districts of Tanzania.

Methods: To capture information about time allocation, 30 WAJA were observed during conventional working hours by research assistants for 5 days each over a period of 4 weeks. Results were presented in term of percentage time allocation for direct client treatment, documentation activities, health education, health promotion non-work-related activities and personal activities.

Results: During routine 8-h workdays, $59.5 \%$ of WAJA time was spent on the provision of health services and other work-related activities. Overall, WAJA spent $27.8 \%$ of their work on traveling from home to home, $33.1 \%$ on health education, $9.9 \%$ of health promotion and only $12.3 \%$ on direct patient care. Other activities related to documentation (7.8\%) and supervision (2.5\%).

Conclusions: Results reflect the pressing obligations of WAJA to engage in activities other than direct work responsibilities during routine work hours. Time spent on work activities is primarily used for health education, promotion, moving between households, and direct patient care. However, greater effort should be directed to strengthening supervisory systems and follow-up of challenges WAJAs facing in order to increase proportion of working hours.
\end{abstract}

Keywords: Community health worker, Time use, Connect project, Tanzania

\section{Background}

Global commitment to primary health care development was accelerated by the 1978 Alma Ata International Conference on Primary Health Care (PHC) and expanded by the proliferation of community health workers (CHW) programs that has spanned three decades. Using a variety of strategies, CHWs have been deployed to implement a range of health service activities and act as agents to foster

\footnotetext{
* Correspondence: ktani@ihi.or.tz

${ }^{\prime}$ Ifakara Health Institute, P.O. Box 78373, Dar es Salaam, Tanzania

Full list of author information is available at the end of the article
}

social change [1-3]. They are typically community members selected to perform functions related to basic preventive, curative, and promotional healthcare delivery $[3,4]$. Most programs around the world rely upon CHWs who have minimal training and have no university-based degree training $[5,6]$. In sub-Saharan African and other developing countries where CHWs are utilized, they receive brief technical training, usually focused on the provision of specialized packages, such as integrated packages (maternal and child health), focused package (antenatal care, newborn and family planning) and specific burden of diseases 
(Tuberculosis, malaria, HIV-AIDS, etc) [3, 7-9]. Their orientation and training range from 5 days to 9 months for programs where CHWs serve as multi-purpose paramedics $[4,10,11]$.

Mounting evidence suggests that CHWs specializes on various health services have improved utilization of those services, for example the uptake of maternal and child health services by increasing community awareness about newborn care, prevention of communicable diseases and the use of rapid diagnostic tests to diagnose and treat malaria $[6-8,12]$. Several important programs involve CHWs in the management of childhood illness [6]. However there are voluntary and salaried CHW. The voluntary dedicate a limited time of about 2 to $4 \mathrm{~h}$ a week differently from salaried, who are full time on targeted intervention [13]. The major factor limiting time devoted by voluntary and salaried $\mathrm{CHWs}$ to the community health works is poor remuneration, supervisions and supplies [14]. A number of countries have either scaled up CHW programs [4] or seek to address the shortage of health workers by expanding $\mathrm{CHW}$ coverage and care $[14,15]$.

Tanzania is one of the countries aiming to increase coverage of health services provision and improve the continuum of care between the community and health facilities through the engagement of CHWs. This is pointed out in a document named Tanzania's Primary Health Care Improvement Policy of 2007 (known by its Swahili acronym, "MMAM"), which calls for the development of a paid official government cadre of CHWs and reinforced in the Health Sector Strategic Plan IV 2015-2020. With development of policy guides, and presence of different types of CHW in Tanzania, the Tanzania Ministry of Health and Social Welfare (MoHSW), the Ifakara Health Institute (IHI) and the Mailman School of Public health of the Columbia University (MSPH-CU), in collaboration with the Tanzania Training Centre for International Health (TTCIH) developed curriculum and trained a standard CHW for 9 month. The trained cadre of CHWs was called Community Health Agents (CHAs) which in Swahili is "Wawezeshaji wa Afya ya Jamii" ("WAJA"). WAJAs are working in three rural districts of Tanzania in randomized cluster trial intervention called Connect Project. The project aims to strengthen the health system by utilizing WAJAs whom they are connecting communities to the health system, with the aim of reducing maternal mortality and improving child health to achieve MDGs 4 and 5 [16].

WAJAs perform a number of activities including health education, health promotion, curative and non-healthrelated work activities such as documentation and preparation of routine reports. Understanding the proportion of time that WAJAs spend on each activity and implication for the amount of time devoted to direct patient care is a key in understanding and strengthening the implementation of the WAJA program. Previous study in Southern Tanzania had shown that a minority of facility health worker time is spent on direct patient care, in spite of its importance relative to other activities [17]. A study from Ethiopia found that health extension workers spent less time at community (37\%) compared to time spent at health post (51 \%) [18]. Another study from rural Ghana showed that community health officers and health extension workers spent only $12 \%$ of their time for direct patient [19]. There is a need of exploring the time spent by $\mathrm{CHW}$ at community as there evidence that even at rural setting the health worker spent less than $1 \%$ of their time in preventive and outreach services [20] that purposely has to be shared and performed by $\mathrm{CHW}$.

The present study focused on understanding how the WAJAs spend their time on all tasks, grouped into community health services activities, other work-related activities and personal activities. In addition, the study assessed the relative proportion of observed CHW activities on maternal and child health services, health education, health promotion and documentation to better understand how the functioning of the WAJA program reflects the project's focus on maternal and child health. This will point the time WAJAs spent at community in this project, and picture out what should be done during scaling up.

\section{Methods}

\section{Study area and setting}

The study took place in the Rufiji, Ulanga and Kilombero districts of Tanzania. In 2012, the Ifakara Health Institute in partnership with Rufiji, Ulanga and Kilombero districts deployed 142 full-time WAJAs, paid an amount equivalent to $\$ 120$ USD per month, through their districts and deployed to some of the villages of these districts. WAJAs were attached to the existing health system and received supportive supervision from the clinicians based at the nearest health facility located within the village or near village. From the project setting the WAJAs received supervision from project coordinator, district $\mathrm{CHW}$ focal person and village supervisor [16].

\section{Participants and sampling}

The WAJAs were selected from their respective villages, trained for 9 months and deployed back to their original villages. They were provided with the essential equipment to facilitate their daily activities, including a bicycle, a mobile phone, malaria rapid diagnostic tests (RDTs), behavior change communication materials, and medicines such as oral rehydration salts, ant-malarias, antibiotics to treat pneumonia, contraceptive pills, condoms etc. More information about the Connect intervention is provided in previous publication [16]. 
The WAJAs participated in this study were drawn from a random selection of 14 out of the 50 villages where WAJAs were deployed. The number of WAJAs in the sampled villages ranged from one to four, and all WAJAs in the selected villages were eligible for participation in the study. A total of 30 WAJAs were working in the 14 selected villages. Participation in the study was voluntarily and written consent was obtained from each participant before the onset of the study.

\section{Measurement tool}

To capture information about time allocation direct observation was used along with a multidimensional work classification tool (Table 1) for sampling activities [20, 21]. This tool facilitates data recording during observation and can facilitate recording of all task to the most detailed. A number of studies have been done using such tools to look at similar issues in developing countries. Woelk and colleagues [22] looked at two urban clinics in Harare and Zimbabwe; Desai and McCaw [23] assessed time use among health workers at health facilities in Jamaica. In Ghana, Frimpong [19] assessed Community Health Officers working at the village level in rural Ghana and in Zambia, Counihan and colleague [8] assessed community health workers who uses RDTs to diagnose malaria. Each of these studies used activity sampling techniques and concluded that facility-based health workers could exercise flexibility in the time they allocated to different tasks. However, none of these studies were on CHWs working full time and tasked with providing multiple services entirely at the household level.

Observation of WAJAs was conducted according to Harvey's description of analysis of time [21] which stipulates that observation of activities must be carried out for a sufficient length of time, and must be recorded, examined and coded along several dimensions. The instrument used to measure WAJA activities in this study was developed with input from the project intervention coordinators and trainers to determine the various activities conducted by WAJAs throughout their typical workdays. A pilot was performed for 2 days to test the applicability of the instrument in Rufiji district. After review of the tool, the teams carried out additional pilot in Rufiji and Kilombero districts to ensure research assistants were conversant with the final tool in each area.

The final classification tool used to observe WAJAs included 78 distinct activities, divided into eight categories that were documentation and reporting, supervision and training, patient care/treatment, individual health education, group health education, WAJA office cleaning and organization, other health work-related activities and lastly WAJA personal activity (Table 1 ).

\section{Data collector training and data collection}

Seven full time research assistants were trained on the use of the observation tool for 1 week. Then a day pilot was organized to test the tool in villages that were not sampled for the study. The observers were equipped to resemble WAJAs, with a bag and bicycle, in order to avoid conspicuousness and maintain a routine community environment as possible. Observers were trained to identify and they were provided with a sheet with a list of all tasks that WAJAs performs and were instructed not to interrupt any conversations or consultations that the WAJAs were engaged in. They were instructed to only ask the WAJAs questions if they were uncertain how to characterize the activity they were engaged in, and to only do so when the WAJA was not attending clients.

WAJAs are full time employees in the village with approximate working hours from 8:00 AM to 4:00 PM from Monday through Friday. Each WAJA was observed for 5 days. Days of observation for an individual WAJA were distributed across a 30-day period and took place on various days of the week to capture a varied sample of WAJA activities. Observation of each WAJA was conducted by the same research assistant for each of the 5 days of observation. Research assistants were present to observe WAJA activities from 8:00 AM until up to 5:00 PM, and completed observation when the WAJA finished their work for the day. Observations of WAJA activities were recorded in 10 min intervals. Research assistants selected the activity in the observation tool, that was most applicable to the activity being performed by the WAJA at the beginning of each interval, and recorded the activity code against the time of the observation. Data collection was done between July and August 2013, which was the harvest and dry season.

All procedures used in this study adhere to the STROBE guideline for reporting observation studies [24].

\section{Analysis}

Two research assistants entered the data into EpiData and then transferred the data into Stata 12 using Stata transfer. Stata 12 was used to clean data; analysis was done using Stata 12 and Microsoft Excel. Analysis involved tabulations of the different activities performed by the WAJAs during observation to arrive at average amounts of time spent on each activity across the standard work day. Results were presented in term of figures and tables.

\section{Results}

The attribute and pattern of WAJA working in the area shows that they are secondary school graduates. They are permanent residency of the villages were working. WAJA observed to be dedicated to their work all days of the week, with planned schedule from Monday to Friday. 
Table 1 Direct Observation Activity Classification Guide

\begin{tabular}{|c|c|}
\hline Code & Activity \\
\hline & 1. Documentation and Reporting \\
\hline 10 & Documentation (writing in register, patient books) \\
\hline 11 & Completing monthly reports \\
\hline \multirow[t]{2}{*}{12} & Other documentation and reporting related activity \\
\hline & 2. Supervision and Training \\
\hline 21 & Visit from Village Supervisor \\
\hline 22 & Visit from Facility Supervisor \\
\hline 23 & Visit from Intervention Coordinator \\
\hline 24 & Visit from WAJA focal person \\
\hline 25 & Phone call with Village Supervisor \\
\hline 26 & Phone call with Facility Supervisor \\
\hline 27 & Phone call with Intervention Coordinator \\
\hline 27 & Phone call with WAJA focal person \\
\hline 29 & Training from the project \\
\hline 210 & Training from other stakeholders \\
\hline \multirow[t]{2}{*}{211} & Other supervision/training related activity \\
\hline & 3. Patient Care/Treatment \\
\hline 31 & Family Planning provision \\
\hline 32 & Deworming \\
\hline 33 & Examination/Treatment of disease or injury (under 5) \\
\hline 34 & Examination/Treatment of disease or injury (over 5) \\
\hline 35 & Talking to patient, but non-health related \\
\hline 36 & Travel with referred patient/patient related \\
\hline \multirow[t]{2}{*}{37} & Other patient care/treatment related activity \\
\hline & 4. Individual Patient Health Education and Counseling \\
\hline 41 & Pregnant client - Healthy pregnancy \\
\hline 42 & Pregnant client - Safe delivery \\
\hline 43 & Pregnant client - Newborn care \\
\hline 44 & Pregnant client - Breastfeeding \\
\hline 45 & Pregnant client - Family Planning \\
\hline 46 & Pregnant client - Other \\
\hline 47 & Postnatal - Newborn care \\
\hline 48 & Postnatal - Breastfeeding \\
\hline 49 & Postnatal - Family Planning \\
\hline 410 & Postnatal - Other \\
\hline 411 & Immunizations/Vitamin A \\
\hline 412 & Growth monitoring (consult weight for age chart) \\
\hline 413 & Family Planning \\
\hline 414 & Malaria (bednet use, symptoms, treatment) \\
\hline 415 & U5 illness (diarrhea, pneumonia) \\
\hline 416 & Deworming \\
\hline 417 & Nutrition \\
\hline 418 & HIV/AIDS related education \\
\hline 419 & Clean environment, personal hygiene, and sanitation \\
\hline
\end{tabular}

Table 1 Direct Observation Activity Classification Guide (Continued)

420
Health insurance promotion

Other disease/Injury/treatment information

Talking to patient, but non-health related

5. Group Health Education and Counseling

Healthy pregnancy

Safe delivery

Newborn Care

Breastfeeding

Immunizations/Vitamin A

Growth monitoring

Malaria (bednet use, symptoms, treatment)

U5 illness (diarrhea, pneumonia)

Family Planning

Deworming

Nutrition

HIV/AIDS related education

Clean environment, personal hygiene, and sanitation

Health insurance promotion

Other disease/Injury/treatment information

Talking to group but non-health related

6. Cleaning/Organization

Cleaning of supply room/cupboard

Organizing supplies

Other sanitation/organization related activity

7. Other Work-Related Activities

Travel or moving between households and supply room

Other work-related travel

Assisting facility outreach services

Bicycle repair

Individual work for drafting work plan/schedule

Discussion with other WAJAs to form work plan

Communication with other WAJA (in-person or by phone)

Communication with village health committee

Communication with staff from a program/project

Attending village council meeting

Attending village health committee meeting

Attending health facility governing committee meeting

8. Non-Work Related Activities

Lunch or Break

Non-work related communication

WAJA closed/left for the day

Personal activities or travel (non-work related) 
Six WAJA declared to attend a number of cases after 4.00 PM and over the weekend at their houses and even at mid night in case of emergencies.

About 93.3 \% (28 out of 30) of sampled WAJAs agreed to participate in the study and were observed. The 2 WAJAs missed were on maternal and annual leave. During work hours, WAJAs spent an average of $59.5 \%$ of their time on community health service activities that is health activities (53.4\%) (Treatment, health education, health promotion and documentation) and related community work activities $(6.1 \%)$ (socialization and repair bicycle). The socialization is related to greetings and talking with members of the household before any health activity and also to WAJA participation to overall village ceremonies (funerals for example). The remaining $40.5 \%$ of WAJA time activity are non-work-related activities such as personal errands, farming, or taking care of their families (Fig. 1).

The Fig. 2 excludes the personal activities done within the working time boundary. The large portion of time allocation of WAJA time was spent traveling from one household to another about $27.8 \%$. WAJAs allocated the most time on maternal health education (20.0\%), underfive health education (8.7\%), health promotion (9.9\%), and documentation and office activities (7.8\%). Other health-related work activities observed including supervision $(2.5 \%)$, health education not focused on maternal and child health topics (4.3) and break (3.5\%). In overall, WAJAs spent $42.9 \%$ of their time on health education and promotion while the direct patient care was devoted to only $12.3 \%$ of the total working duration (Fig. 2).

Figure 3 presents the average distribution of time allocation for each hourly period of the standard working day. Most of WAJA health service activities, including maternal health education, under-five health education and health promotion, were concentrated between 9:00 AM and

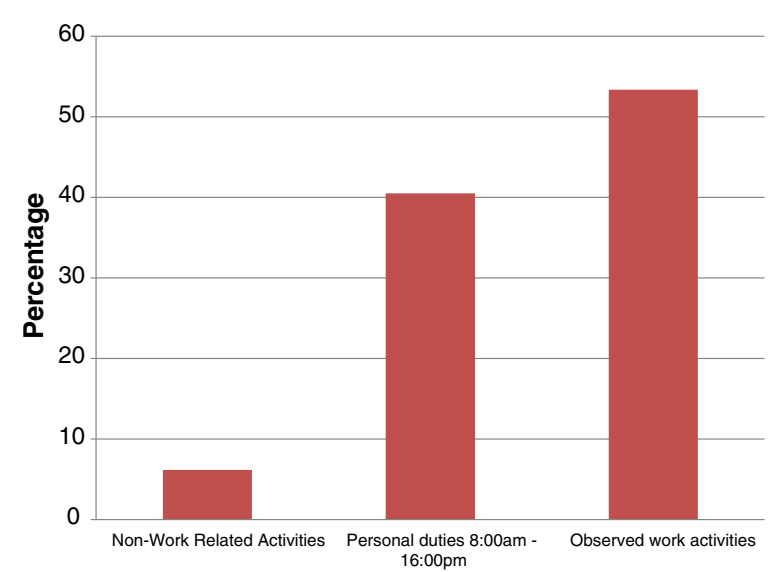

Fig. 1 Mean proportion of working time over the hours from 8:00 AM - 4:00 PM
12:00 PM. From 8:00 AM to 9:00 AM, WAJAs spent an average of $60 \%$ of their time providing health services. This increases to about $85 \%$ between 9:00 AM and 11:00 AM, and then declines over the afternoon to less than $10 \%$ by 4:00 PM. Personal activities like taking care of family and farming occurred mainly at the beginning of the day and after 2:00 PM. From 3 PM, WAJAs spent $90 \%$ of their time on personal activities.

\section{Discussion}

This study is one of the few studies to examine time use among CHWs and the first for those professionalized and salaried in Tanzania [16]. The finding that WAJAs are engaged in work-related activities for only $59 \%$ of their working hours may be partly attributed to the fact that WAJAs are a new cadre in the Tanzanian health system and therefore require extensive supportive supervision and follow up [25] to ensure productivity. Because WAJAs are new to these responsibilities, they are in need of an enabling environment and quality support from the system $[25,26]$. Typically, CHWs work in specific programs for an abbreviated period of time $[14,27]$ rather than as full-time, paid employees appeared to use few hours. Future implementation and scale-up of the WAJA program requires an understanding of the factors constraining the proportion of time that WAJA spend on community health services in the context of their full-time employment.

Findings showed that large portion of time been devoted is on promotion and preventive cases has also been observed by other study in Ethiopia [18]. The communities are surrounded by a number of health issues that need daily clarification and reminds. These are issues like maternal education, under five health education and other health promotion of which CHWs invest more time on them [18] compared to facility based staff even working in rural setting [20].

Our study found that traveling from one household to another appear to take a large portion of WAJA time similar to that of Odendaal in South Africa [28] and may be related to the dispersed settlement patterns of the study communities in which the WAJAs provide services at the doorstep level. Supervision appeared small as this cadre was designed to work independently in a community for the large part of the time. Similar study done in Ghana documented that, less frequently of supervision reduces the volume of care by health workers working alone even at health facilities [19]. Supervision as one of human resource management component is important as it creates a chance for discussion on challenging areas when services delivery.

\section{Limitations}

This study is based on a relatively small number of participants and estimates of their working time are subject 


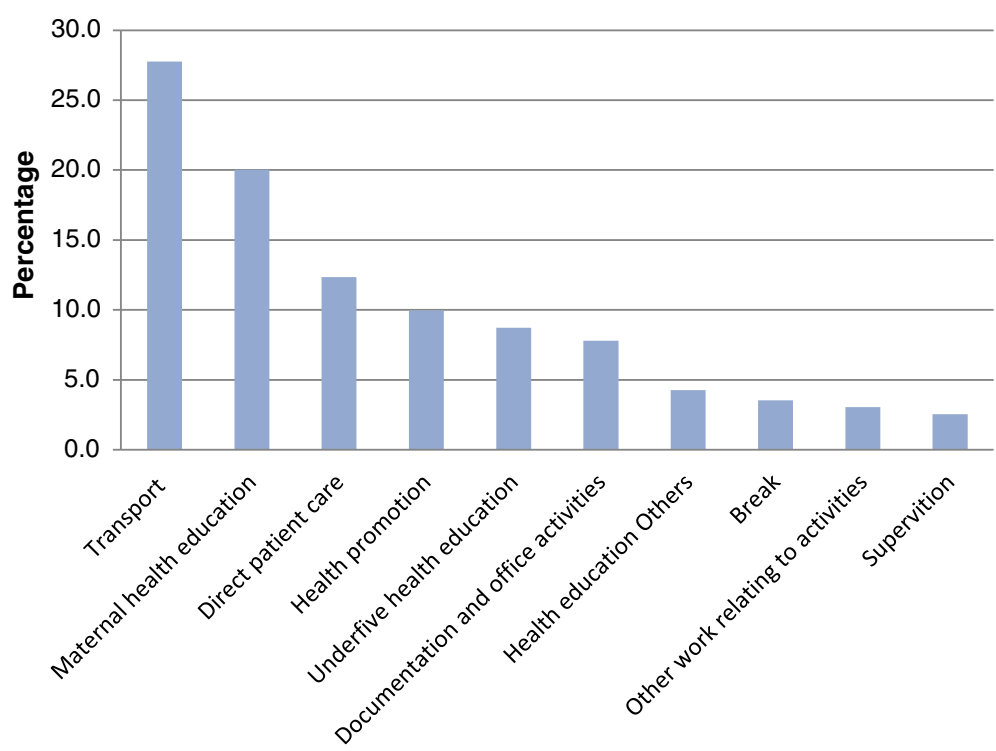

Fig. 2 WAJA time use breakdown, 8.00 AM-4.00 PM to each category of community 416 health service work

to a number of definitions and boundaries. In this case, boundaries have been influenced by the working location and preset working hours from 8:00 AM to 4:00 PM. Our study was unable to address the fact that WAJAs sometimes work outside the normal range of working hours, and therefore did not measure their activities offhours such as response to emergencies, emergency provision of first aid and advice.

Another limitation is the fact that the study took place within a 30-day period, and therefore seasonal variations could not be observed. This study was conducted just after the end of the harvest season in Rufiji district and during the harvest season in Kilombero and Ulanga districts. Patterns of illness and WAJAs responses were therefore only representative of this small portion of the year. WAJA activities during the observed harvest and post-harvest seasons may have important differences compared to the rainy seasons when cultivation is taking place, because at this time, community members often reside on farms far away from their permanent homes. Understanding variation in WAJA time use in response to seasonal factors is important in this setting where the majority of community members are subsistence farmers.

Finally, the direct observation methods employed by this study are limited, that is WAJAs may have modified their work routines in response to the presence of the research assistants observing their work. Rather than capturing a sampling of actual WAJA work routines, direct observation rather captures a sampling of WAJA work routines in the presence of a research assistant given the task of observing their work. While this method may not capture a completely accurate portrayal of WAJA work routines,

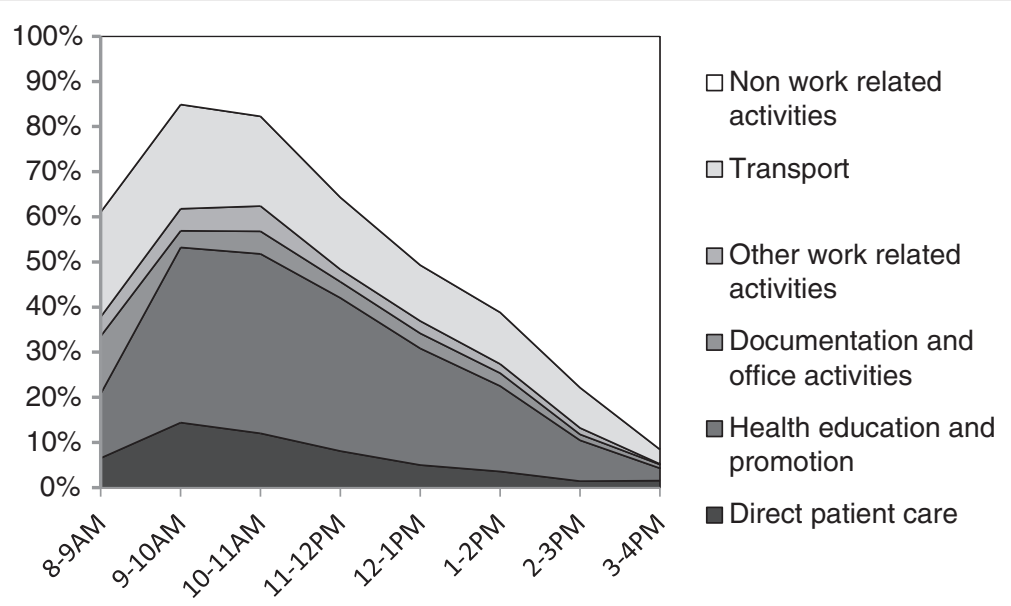

Fig. 3 Mean hourly distribution of time allocation by activity per day 
direct observation is considered more reliable than WAJA self-reports of their time use [24].

\section{Conclusion}

WAJA are a new cadre playing a crucial role in linking communities to the health system. This study observed that WAJAs spent a large portion of their time as intended in health education and promotion. However, greater effort should be directed to strengthening supervisory systems and follow-up of challenges WAJAs facing in order to increase the proportion of working hours spent on provision of services to their clients each day. In addition, it will be important to identify factors that facilitate and or hinder WAJA activities seasonally, as they work in rural area where most clients are subsistence farmers who move to their farms.

\section{Acknowledgements}

We sincerely thank the study participants (WAJA), and members of the Connect project, including Ruth Wilson, Awena Malendo, Dominick Mboya, Doroth Maganga and Samweli Likasi, for their cooperation during data collection.

\section{Funding}

The Connect Project is funded by the Doris Duke Charitable Foundation and Comic Relief.

\section{Availability of data and materials}

All principle results are within the manuscript in the form of figures. The data can be accessible based on request.

\section{Authors' contributions}

$K T$ conceptualized the research question, designed the study, collected data, executed data analysis and drafted the manuscript. AS participated in designing the study and provided critical review of the manuscript. AMK and JFP designed the primary study and critically reviewed and revised the manuscript together with $A E, C B$ and $M N$. All the authors read and approved the final draft of the manuscript.

\section{Competing interests}

The authors declare that they have no competing interests. All authors reviewed the manuscript prior to publication. The funders had no role in the design of this study; collection, management, analysis and interpretation of the data or the conduct of this study or preparation or approval of the manuscript.

\section{Consent for publication}

Not applicable.

\section{Ethics approval and consent to participate}

The Ifakara Health Institute's Institutional Review Board (IHI/IRB/No.16-2010), the National Institute for Medical Research of the Medical Research Coordinating committee (NIMR-CC) (NIMR/HQ/R.8a/Nol.IX/1203) and the Columbia University Medical Center Institutional Review Board (Protocol AAAF3452) all have approved this study. Participant in this was WAJA and the study focused only on WAJA activities. And before it started the WAJA were asked their consent on the first day of observation. No patient-related information was identified, assessed or recorded, so the patient was not asked for consent as they were not subject of the study. Observers were instructed to give privacy to WAJA clients during their consultations. If clients wanted privacy, the observer was instructed to leave and later ask the WAJA about the activity done and noted such observations as activities that were indirectly observed.

\section{Author details}

${ }^{1}$ Ifakara Health Institute, P.O. Box 78373, Dar es Salaam, Tanzania. ${ }^{2}$ Heilbrunn Department of Population and Family Health, Mailman School of Public Health, Columbia University, New York, USA.

Received: 9 November 2015 Accepted: 25 June 2016

Published online: 01 September 2016

\section{References}

1. van Ginneken N, Lewin S, Berridge $V$. The emergence of community health worker programmes in the late apartheid era in South Africa: An historical analysis. Soc Sci Med. 2010;71(6):1110-8.

2. Christopher $J B_{\text {, et }}$ al. Thirty years after Alma-Ata: a systematic review of the impact of community health workers delivering curative interventions against malaria, pneumonia and diarrhoea on child mortality and morbidity in sub-Saharan Africa. Hum Resour Health. 2011;9(1):27.

3. Hoke T, et al. Community-based distribution of injectable contraceptives: introduction strategies in four sub-Saharan African countries. Int Perspect Sex Reprod Health. 2012;38(4):214-9.

4. Johnson $\mathrm{CD}$, et al. Learning from the Brazilian community health worker model in North Wales. Global Health. 2013;9:25.

5. Chopra $\mathrm{M}$, et al. Effects of policy options for human resources for health: an analysis of systematic reviews. Lancet. 2008;371(9613):668-74.

6. Lewin S, et al. Lay health workers in primary and community health care for maternal and child health and the management of infectious diseases. Cochrane Database Syst Rev. 2010;3:CD004015.

7. Mubi M, et al. Malaria rapid testing by community health workers is effective and safe for targeting malaria treatment: randomised cross-over trial in Tanzania. PLOS one. 2011;6(7). http://journals.plos.org/plosone/ article?id=10.1371\%2Fjournal.pone.0019753.

8. Counihan $\mathrm{H}$, et al. Community health workers use malaria rapid diagnostic tests (RDTs) safely and accurately: results of a longitudinal study in Zambia. Am J Trop Med Hyg. 2012;87(1):57-63.

9. Tran NT, et al. Developing capacities of community health workers in sexual and reproductive, maternal, newborn, child, and adolescent health: a mapping and review of training resources. PLoS One. 2014;9(4):e94948.

10. O'Brien MJ, et al. Role development of community health workers: an examination of selection and training processes in the intervention literature. Am J Prev Med. 2009;37(6 Suppl 1):S262-9.

11. Najafizada S, Labonte R, Bourgeault I. Community health workers of Afghanistan: a qualitative study of a national program. Confl Heal. 2014;8(1):26.

12. Medhanyie A, et al. The role of health extension workers in improving utilization of maternal health services in rural areas in Ethiopia: a cross sectional study. BMC Health Serv Res. 2012;12:352.

13. Cherrington A, et al. Recognizing the diverse roles of community health workers in the elimination of health disparities: from paid staff to volunteers. Ethn Dis. 2010;20(2):189-94.

14. Greenspan JA, et al. Sources of community health worker motivation: a qualitative study in Morogoro Region, Tanzania. Hum Resour Health. 2013;11:52.

15. Guilbert JJ. The World Health Report 2006: working together for health. Educ Health (Abingdon). 2006:19(3):385-7.

16. Ramsey K, et al. The Tanzania Connect Project: a cluster-randomized trial of the child survival impact of adding paid community health workers to an existing facility-focused health system. BMC Health Serv Res. 2013;13 Suppl 2:S6.

17. Manzi F, et al. Human resources for health care delivery in Tanzania: a multifaceted problem. Hum Resour Health. 2012;10:3.

18. Mangham-Jefferies $L$, et al. How do health extension workers in Ethiopia allocate their time? Hum Resour Health. 2014;12:61.

19. Frimpong JA, et al. Does supervision improve health worker productivity? Evidence from the Upper East Region of Ghana. Trop Med Int Health. 2011;16(10):1225-33.

20. Bryant M, Essomba RO. Measuring time utilization in rural health centres. Health Policy Plan. 1995:10(4):415-22.

21. Harvey A. The measurement and analysis of time use. Soc Indic Res. 1990; 23(4):303-8.

22. Woelk $\mathrm{GB}$, et al. An activity sampling study of primary care staff of two Harare polyclinics. Cent Afr J Med. 1986;32(5):126-9.

23. Desai P, McCaw AM. Proportion of time used productively by staff in Jamaica's primary health care services. West Indian Med J. 1987;36(2):80-5. 
24. von Elm E, et al. The Strengthening the Reporting of Observational Studies in Epidemiology [STROBE] statement: guidelines for reporting observational studies. Gac Sanit. 2008;22(2):144-50.

25. Jaskiewicz W, Tulenko K. Increasing community health worker productivity and effectiveness: a review of the influence of the work environment. Hum Resour Health. 2012;10(1):38.

26. Hill Z, et al. Supervising community health workers in low-income countries-a review of impact and implementation issues. Glob Health Action. 2014;7:24085.

27. Mwai GW, et al. Role and outcomes of community health workers in HIV care in sub-Saharan Africa: a systematic review. J Int AIDS Soc. 2013;16(1):18586.

28. Odendaal WA, Lewin $\mathrm{S}$. The provision of TB and HIV/AIDS treatment support by lay health workers in South Africa: a time-and-motion study. Hum Resour Health. 2014;12:18.

Submit your next manuscript to BioMed Central and we will help you at every step:

- We accept pre-submission inquiries

- Our selector tool helps you to find the most relevant journal

- We provide round the clock customer support

- Convenient online submission

- Thorough peer review

- Inclusion in PubMed and all major indexing services

- Maximum visibility for your research

Submit your manuscript at www.biomedcentral.com/submit
Biomed Central 